\title{
Quality of online self-management resources for adults living with primary brain cancer, and their carers: a systematic environmental scan
}

Isabelle Schaefer ${ }^{1}$, Nicole Heneka ${ }^{1}$, Tim Luckett ${ }^{1}$, Meera R. Agar ${ }^{1}$, Suzanne K. Chambers ${ }^{2}$, David C. Currow ${ }^{1}$, Georgia Halkett ${ }^{3}$, Domenica Disalvo', Ingrid Amgarth-Duff', Cleola Anderiesz ${ }^{4}$ and Jane L. Phillips ${ }^{1 *}$ (D)

\begin{abstract}
Background: A primary brain cancer diagnosis is a distressing, life changing event. It adversely affects the quality of life for the person living with brain cancer and their families ('carers'). Timely access to evidence-based information is critical to enabling people living with brain cancer, and their carers, to self-manage the devastating impacts of this disease.

Method: A systematic environmental scan of web-based resources. A depersonalised search for online English-language resources published from 2009 to December 2019 and designed for adults (> 25 years of age), living with primary brain cancer, was undertaken using the Google search engine. The online information was classified according to: 1) the step on the cancer care continuum; 2) self-management domains (PRISMS taxonomy); 3) basic information disclosure (Silberg criteria); 4) independent quality verification (HonCode); 5) reliability of disease and treatment information (DISCERN Sections 1 and 2); and readability (Flesch-Kincaid reading grade).

Results: A total of 119 online resources were identified, most originating in England ( $n=49)$; Australia $(n=27)$; or the USA ( $n=27)$. The majority of resources related to active treatment $(n=76)$, without addressing recurrence $(n=3)$, survivorship $(n=1)$ or palliative care needs $(n=13)$. Few online resources directly provided self-management advice for adults living with brain cancer or their carers. Just over a fifth $(n=26,22 \%)$ were underpinned by verifiable evidence. Only one quarter of organisations producing resources were HonCode certified $(n=9,24 \%)$. The median resource reliability as measured by Section 1, DISCERN tool, was 56\%. A median of 8.8 years of education was required to understand these online resources.

Conclusions: More targeted online information is needed to provide people affected by brain cancer with practical selfmanagement advice. Resources need to better address patient and carer needs related to: rehabilitation, managing behavioural changes, survivorship and living with uncertainty; recurrence; and transition to palliative care. Developing online resources that don't require a high level of literacy and/or cognition are also required.
\end{abstract}

Keywords: Brain neoplasms, Consumer health information, Self-management, Cancer, Online

\footnotetext{
* Correspondence: Jane.Phillips@uts.edu.au

'Improving Palliative, Aged and Chronic Care through Clinical Research and Translation (IMPACCT), Faculty of Health, University of Technology Sydney, Sydney, New South Wales, Australia

Full list of author information is available at the end of the article
}

(c) The Author(s). 2021 Open Access This article is licensed under a Creative Commons Attribution 4.0 International License, which permits use, sharing, adaptation, distribution and reproduction in any medium or format, as long as you give appropriate credit to the original author(s) and the source, provide a link to the Creative Commons licence, and indicate if changes were made. The images or other third party material in this article are included in the article's Creative Commons licence, unless indicated otherwise in a credit line to the material. If material is not included in the article's Creative Commons licence and your intended use is not permitted by statutory regulation or exceeds the permitted use, you will need to obtain permission directly from the copyright holder. To view a copy of this licence, visit http://creativecommons.org/licenses/by/4.0/. The Creative Commons Public Domain Dedication waiver (http://creativecommons.org/publicdomain/zero/1.0/) applies to the data made available in this article, unless otherwise stated in a credit line to the data. 


\section{Background}

In $2018,296,851$ people across the world were diagnosed with brain cancer and 241,037 died as a result of this cancer [1]. Globally, little progress has been made in improving five-year survival rates for primary brain cancer ('brain cancer') [2]. Even in long-term survivors, cognitive and physical disability associated with brain cancer can be profound. The overall disease burden from brain cancer has been estimated as 7.7 million disability-adjusted life years [3]. As many adults are of working age, with a partner, children, other family and financial responsibilities, a brain cancer diagnosis impacts adversely on every aspect of the person's life, as well as those of their family and carer(s) ('carers') [4].

The information needs of people living with brain cancer, and their carers, change according to their phase of disease $[5,6]$. The Australian National Service Improvement Framework for Cancer [7] identifies key intervention points across the cancer care continuum, namely: reducing risk, finding cancer early, care between and after treatment, and end of life care. People diagnosed with high grade glioma and other cancers find it difficult to process complex prognostic information, and experience a strong and pressing need for information including treatment options, side effects and prognosis $[5,6,8]$.

Much of this need for timely information is driven by the desire of people with any type of cancer to make informed decisions and to plan accordingly, but also to shape the questions to ask clinicians before and after the initial consultation [8-10]. People with high grade brain cancers require information early in the disease course to enable them and their carers to adjust to their sudden and profound reduction in independence due to: decline in cognitive function; changes in physical abilities including onset of seizures and balance problems; reduced ability to work or drive and associated loss of income, as well as the emotional toll of their diagnosis $[6,11]$. Later in the cancer care continuum, people with brain cancer and their carers require access to information to help them self-manage their symptoms such as fatigue and memory deficits that can vary in severity over time, maintain emotional well-being and independently undertake activities of daily living as much as possible. Long-term brain cancer survivors and their carers need information on strategies for rehabilitation and management of long term symptoms including difficulty assimilating and remembering information $[6,12,13]$. Given the high rate of recurrence in brain cancers, information on palliation and end of life care is also critical for both people with brain cancer and their carers $[13,14]$.

Online searching for information is often the first step people with newly diagnosed cancer of any type independently undertake in order to start to understand the implications of their condition and/or symptoms [15].
People living with any cancer, and their carers, often rely on online resources to supplement information and advice provided by clinicians, despite the fact that online resources may contain misleading or incorrect information [16-18]. However, people living with brain cancer report difficulty in finding and comprehending online information that addresses their needs, including strategies to maintain psychosocial wellbeing and symptom management, particularly in the presence of difficulties in concentration and understanding [6]. The quality and readability of online resources is therefore critical to ensure that people with brain cancer and their carers have access to appropriate, accurate evidenced based information that is easy to comprehend and integrate.

Accessing accurate information is essential to supporting the self-management actions people take to cope with their illness [19-22]. Information that contributes to strengthening the person's capacity to self-manage their cancer enables them to: feel more prepared for interventions such as surgery and to cope with their post-operative symptoms; feel confident to participate in medical decision-making; and promotes adherence to recommended treatments $[21,22]$. People who are better informed about their disease have less anxiety and depression, and better self-management and treatment adherence [23, 24].

Upon, and immediately beyond diagnosis, the information received uniquely shapes a person's attitudes to their condition [21]. The provision of timely information initiates an iterative process of learning and implementation that promotes feelings of empowerment and confidence $[25,26]$. The benefits of online information have given rise to a variety of practical online resources available for selfmanagement of illness, including question prompt lists, symptom diaries, exercise and diet programs, and psychotherapeutic and cognitive training resources. However, it remains unclear how many resources are available for adults affected by brain cancer, or the quality of these resources.

\section{Aim}

To appraise the content, reliability and readability of the available online self-management resources for adults living with primary brain cancer, and their carers.

\section{Methods \\ Design}

An environmental scan, conducted and reported in accordance with the PRISMA Statement [27].

\section{Inclusion criteria}

To be included, online consumer resources ('resources') needed to be available free of charge in English and provide text-based advice that an adult (aged $>25$ years) 
living with brain cancer or a caregiver, ('consumer') might use to inform self-management across the brain cancer care continuum [7]. Self-management was defined in terms of the 14 domains identified by the Practical Reviews in Self-Management Support (PRISMS) taxonomy [28]. Included resources needed to contain at least one PRISMS component addressing practical self-management (components A2-A14, see Table 2). Resources that only comprised information about disease (component A1), and no other PRISMS components, were excluded to maintain focus on practical self-management advice. Resources did not need to specify phase of disease management or age, but those specific to non-adult populations managing brain cancer (e.g., paediatric, adolescent and young adult (aged 15-24 years) were excluded, due to their specific developmental needs. Additionally, resources directly referring to cerebral metastases, or benign tumours (WHO Grade I) were excluded [29].

To improve confidence in the currency and quality, resources had to be developed from 2009 onwards, and originate from countries identified as being within the top twenty for five-year brain cancer survivorship by the Global surveillance of trends in cancer survival 2000-14 (CONCORD-3) [2].

\section{Searches}

The web-based search was conducted using the Google search engine, in the Google Chrome web browser. Searches were depersonalised by adding "\&pws $=0$ " to the URL to prevent tailoring of results to user or computer. The search strategy incorporated the name of each country, and variations of 'brain cancer' and specific tumour types as identified in a systematic review of brain cancer research [30].

\section{Data collection and analysis}

Data collection and analysis was undertaken by three authors (IS, DS and IAD). A subset of resources were cross-checked between additional authors (TL and JLP), and discrepancies resolved by discussion with the larger author team. Data on relevant resources were extracted into an MS Excel spreadsheet to capture country of origin, organisation name, resource name and URL. The format of the resource (web page or digital document $[\mathrm{PDF}]$ ) and organisation type (charity, government, professional, commercial) were also recorded. The focus of the information was classified according to phase of the cancer care continuum, with the addition of subdomains specific to care of people with brain cancer identified through thematic content analysis [7]. Selfmanagement content was categorised according to the PRISMS taxonomy [28].

The quality of resources was appraised using the following quality assessments.
- Silberg Criteria [31]: The availability of information needed for a consumer to judge the quality of a resource were rated using the four criteria developed for online heath information: date of publication, authorship, reference to evidence and disclosure of competing interests. These criteria represent the minimum core standards that should be met by online health resources to enable consumers to assess whether a resource is reliable and accurate [26].

- HonCode Certification [32]: Provided by the Health on the Net Foundation, websites are evaluated by medical experts using eight principles: authority, complementarity, confidentiality, attribution, justifiability, transparency, financial disclosure and advertisement policy. Certification indicates that a website provides detailed information about the developing organisation, and that health information is complete, balanced and transparent. This was measured using the HonCode toolbar [33].

- DISCERN tool [34]: To assess the quality of each resource in detail, sections one and two of the DISC ERN tool were used. The DISCERN tool is a three-part tool designed for consumers to rate the reliability of written health information [34]. This tool was modified to include a three-point scale $(0=$ lowest; 1 = partial; 2 = highest $)$ after finding seven-points to be too fine grained to reliably rate. Resources were rated by clarity, transparency, bias, scope and referral to further information (Section 1); and balance/thoroughness of treatment information (Section 2). Section 3, a global rating score, was not included so that all resources were rated in the same way.

- Flesch-Kincaid reading grade tool [35]: This tool uses a formula to rate the complexity of text and estimates the grade/year of education (United States) required to understand the text for ease of interpretation [35]. Text from resources was copied into a MS Word document. Any complex elements such as web URLs, phone numbers or addresses were removed. Text from bullet points was retained, but converted into single sentences. The text was then analysed by an online calculator [36].

When reporting overall quality, the DISCERN Section 1 score rating clarity, transparency, bias and use of references to evidence was used [34]. This was designed to enable all resources to be graded consistently by the same overall measure. Resources were divided into quartiles to facilitate identification of the highest ranking resources.

\section{Results}

A total of 741 resources were identified during the search, of which 119 met the inclusion criteria (Refer 
Fig. 1). A summary of data analysis is provided in Additional file 1.

Resources for consumers about self-management for people living with brain cancer and their carers were developed in England $(n=49)$, Australia $(n=27)$, the US $(n=27)$, Canada $(n=11)$, Ireland $(n=3)$ and Scotland $(n=2)$.

\section{Cancer care continuum}

The majority of resources available for adults living with brain cancer, and their carers, comprised topics relating to 'active treatment' $(n=76)$ and 'care between and after treatment' $(n=121)$ (Refer Table 1). Palliative and end-of-life care $(n=13)$ and assessment and management of recurrent disease $(n=3)$ had the smallest number of resources across the cancer care continuum, while long-term survivorship $(n=1)$ considerations were the least described sub-domains.

\section{Prisms}

Most resources $(n=80,60 \%)$ for adults with brain cancer and their carers included basic information about the nature and treatment of the disease (Refer Table 2). Just under half $(n=62,47 \%)$ included lifestyle advice and support and approximately one third $(n=46$, $35 \%$ ) included information about available resources. No resources provided information on accessing equipment to support daily life, and few resources promoted regular review $(n=1,1 \%)$ or symptom tracking with clinical review $(n=2,2 \%)$.

\section{Silberg criteria scores}

Half $(n=67,50 \%)$ of the resources fulfilled more than half $(\geq 3)$ of Silberg's criteria, but only one tenth $(n=14$, $11 \%$ ) fulfilled all four minimal reporting criteria for online health information. All resources recorded the funding or developing organisation, however just under three-quarters $(n=95,71 \%)$ included details about when the resource was published or last updated. Only a third $(n=48,36 \%)$ included information about authorship and one quarter $(n=37,28 \%)$ referenced reliable evidence used to develop resource.

\section{HonCode certification}

Only one quarter $(n=9,24 \%)$ of the organisations $(n=32)$ that developed the identified resources were HonCode certified.

\section{DISCERN sections 1 and 2}

\section{Section 1}

Median percentage score resource reliability was $56 \%$ (range 25-100\%) (Refer Fig. 2). Sixty eight percent of the identified resources had a clearly defined purpose. The resources often contained information about additional support services or information providers relevant to people living with brain cancer and their carers. Resources often did not cite reliable health information to support content $(n=92,77 \%)$, or when cited evidence was published $(n=84,71 \%)$. Eighty three percent of resources were rated as mostly or entirely balanced and unbiased $(n=99)$. However, resources rarely referred to

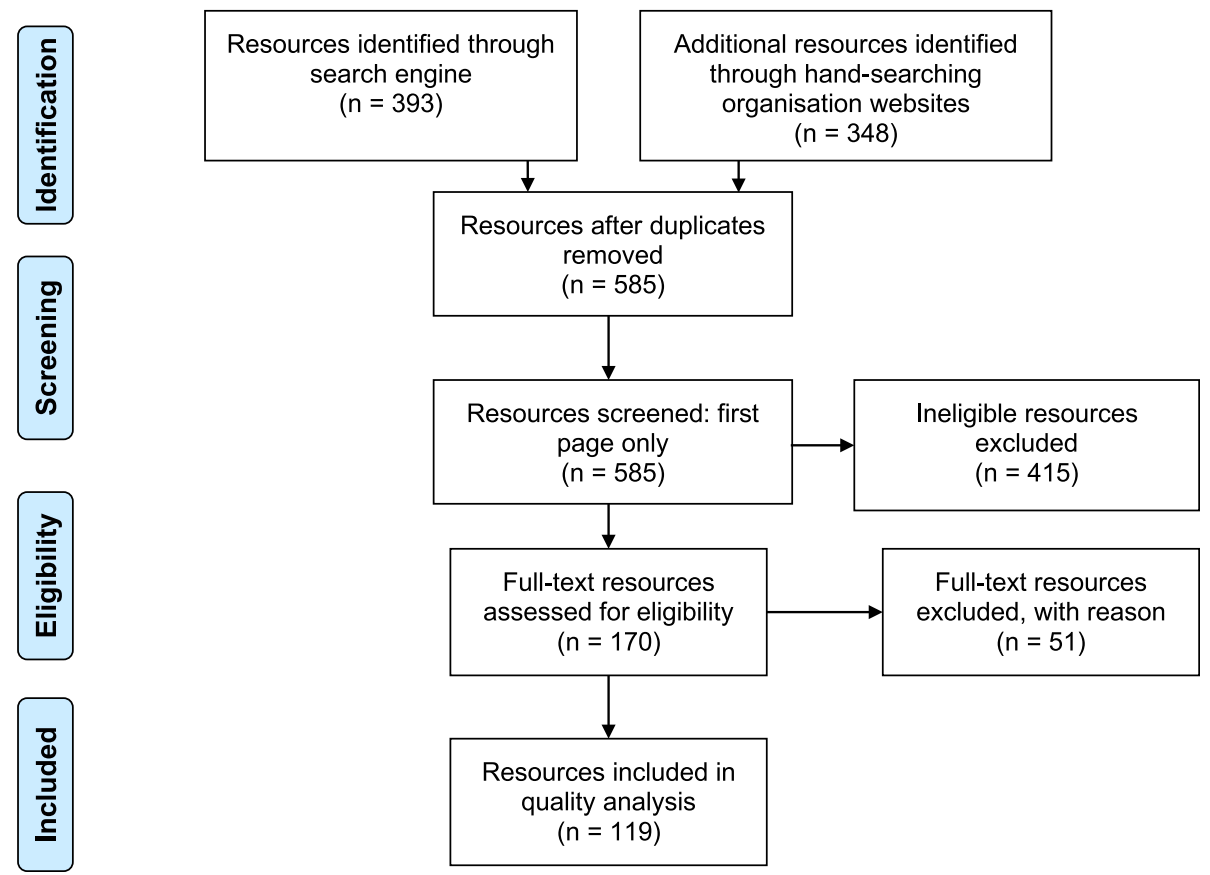

Fig. 1 PRISMA flowchart showing screening and eligibility assessment 
Table 1 Resources mapped to cancer care continuum by subdomain $(N=119)$

\begin{tabular}{ll}
\hline Phases of Cancer Continuum [7] & $\begin{array}{l}\text { Number of references } \\
\text { to subdomains } \\
\left(\boldsymbol{n}=\mathbf{1 1 9 ) ^ { \mathbf { a } }}\right.\end{array}$ \\
\hline Find cancer early & $\mathbf{4 3}$ \\
Active treatment & $\mathbf{7 6}$ \\
Surgery & 19 \\
Systemic therapy & 16 \\
Radiotherapy & 19 \\
Supportive care for side effects during & 18 \\
treatment & \\
Alternative and Complementary treatments & 4 \\
Care between and after treatment & $\mathbf{1 3 1}$ \\
Self-efficacy & 15 \\
Carer Support & 12 \\
Care Coordination & 5 \\
Surveillance & 3 \\
Rehabilitation & 36 \\
Long term survivorship & 1 \\
Management of long-term treatment side & 30 \\
effects & \\
Psychosocial care & $\mathbf{1 3}$ \\
Recurrent Disease & $\mathbf{3}$ \\
Palliative and End-of-life care & \\
\hline
\end{tabular}

${ }^{a}$ Total number of discrete resources differs from column total where resources were relevant across more than one point in the cancer care continuum areas of uncertainty such as predicting personal surgical outcomes or treatment responses $(n=15,22 \%)$.

\section{Section 2}

Almost one fifth $(n=22,18 \%)$ of all resources included information about brain cancer treatments. The median DISCERN Section 2 score for the quality and bias of treatment information was $57 \%$ (range 14-93\%). Approximately one third of the resources $(n=6,36 \%)$ rated greater than $70 \%$ for quality of treatment information. A small number of resources $(n=4,18 \%)$ rated less than $30 \%$ for reliability.

Resources often gave a basic description of brain cancer treatment(s) and its benefits $(n=18,82 \%)$. Only one resource mentioned the option of not receiving treatment for brain cancer. Description of impact on quality of life $(n=13,59 \%)$ and support for shared decisionmaking $(n=14,64 \%)$ were included less frequently.

\section{Flesch-Kincaid reading grade level}

The median score for years of education required to understand resources was grade 8.8 (range 4.1-15).

\section{Analysis of top quartile resources}

Resources in the top quartile scored $69 \%$ or above in DISCERN Section 1 (Additional file 1). Number of PRIS MS categories included in resource, Silberg criteria rating and reading grade required were approximately equal when comparing the top quartile resources to resources in the lower quartiles (Refer Table 3). Two thirds $(n=20,66 \%)$ of the top quartile resources were published digital documents (portable document format,

Table 2 Categorisation of resources by PRISMS component $(N=119)$

\begin{tabular}{lll}
\hline PRISMS component & Total number of discrete resources $(\mathbf{N}=\mathbf{1 1 9})^{\mathbf{a}}$ \\
\cline { 2 - 3 } & $\mathbf{n}(\%)$ & $(50 \%)$ \\
\hline A1. Information about condition and /or its management & 66 & $(26 \%)$ \\
A2. Information about available resources & 34 & $(5.3 \%)$ \\
A3. Provision of/agreement on specific clinical action plans & 7 & $(0.8 \%)$ \\
and/or rescue medication & 1 & $(1.5 \%)$ \\
A4. Regular clinical review & 2 & $(6.8 \%)$ \\
A5. Monitoring of condition with feedback & 9 & $(0 \%)$ \\
A6. Practical support with adherence (medication or behavioural) & 0 & $(14 \%)$ \\
A7. Provision of assistive equipment & 19 & $(18 \%)$ \\
A8. Provision of easy access to advice or support when needed & 24 & $(7.5 \%)$ \\
A9. Training/rehearsal to communicate with health-care professionals & 10 & $(14 \%)$ \\
A10. Training/ rehearsal for everyday activities & 19 & $(32 \%)$ \\
A11. Training/ rehearsal for practical self-management activities & 42 & $(17 \%)$ \\
A12. Training/ rehearsal for psychological strategies & 22 & $(44 \%)$ \\
A13. Social support & 58 & \\
A14. Lifestyle advice and support &
\end{tabular}

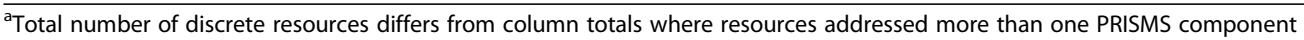



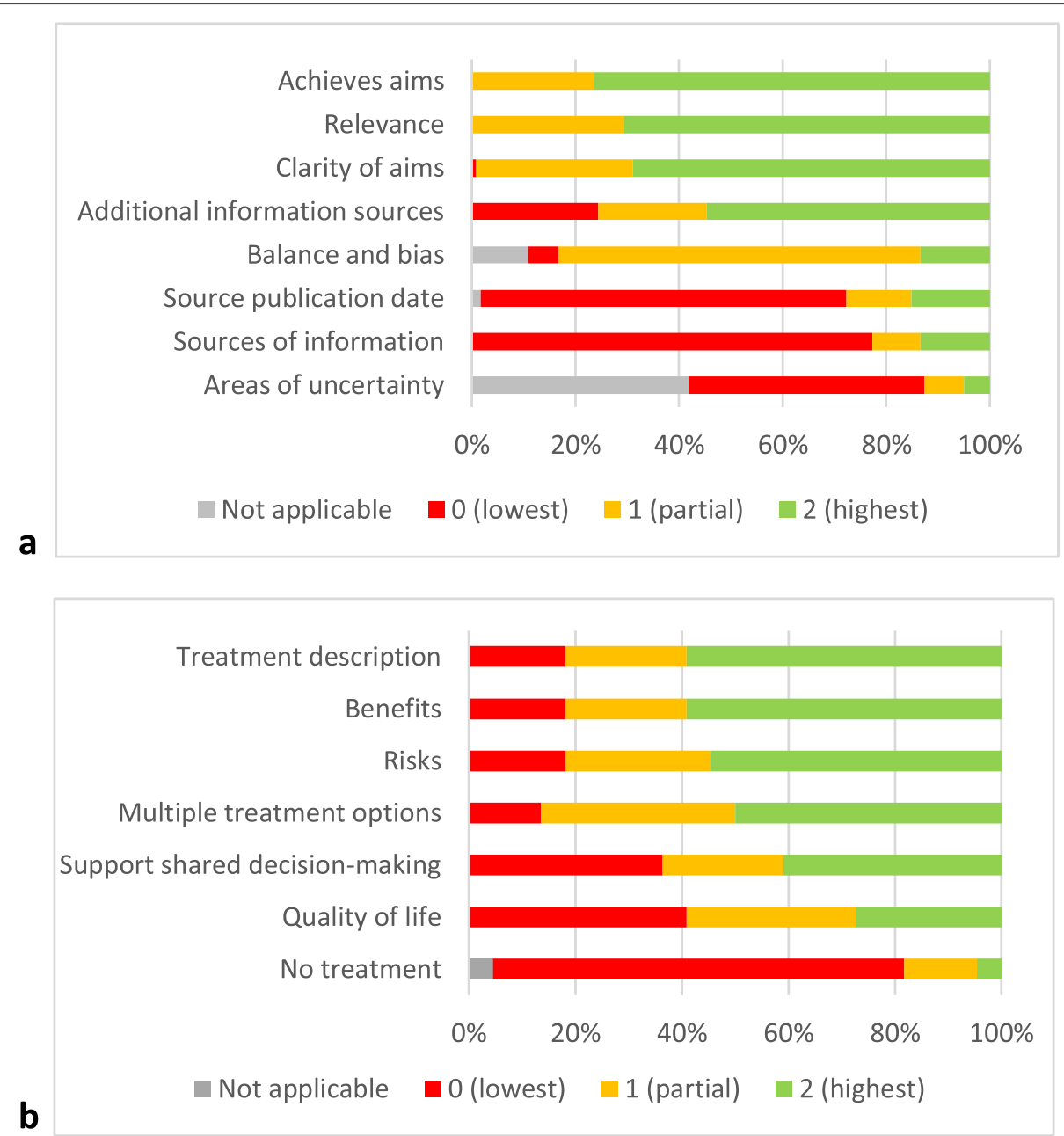

Fig. 2 Quality analysis of resources using DISCERN Section 1 (Panel $\mathbf{a}, n=119)$, and DISCERN Section 2 (Panel $\mathbf{b}, n=22$ )

[PDF]). Compared to the three lower quartiles, the resources in the top quartile were more likely to include a publication date (93\% vs $63 \%)$ and verifiable evidence to support content ( $73 \%$ vs $3 \%)$.

\section{Discussion}

This environmental scan found that self-management resources for people living with brain cancer often did not adhere to minimum reporting standards for online health information [31]. As a result, people living with brain cancer, and their carers, may find it difficult to judge quality and reliability, and the existing online information may not address their evolving needs throughout the different phases of their disease.

Content did not equally cover all phases of the cancer care continuum, and contained very little practical selfmanagement advice to assist people living with brain cancer to play an active role in their care. In addition this environmental scan found that few resources were underpinned by verifiable evidence, or tailored to address the needs of people with cognitive impairment from culturally and linguistically diverse backgrounds or First Nations people.

\section{Distribution across cancer care continuum}

The identified self-management resources did not equally address the whole brain cancer care continuum. While desire for information is highest at the time of diagnosis, information needs persist as people with cancer transition between management phases, undertake new treatments or therapies, or disease management changes [5]. However, resources identified in this study most often addressed issues in the early to intermediate phases of brain cancer management; encompassing diagnosis, treatment choices, decision-making, care coordination and side effect management. In comparison, resources that spoke to the unique needs of brain cancer survivors were lacking, such as specific post-treatment self-management strategies for people with no sights of active disease. 
Table 3 Comparison of resources by quartile $(N=119)$

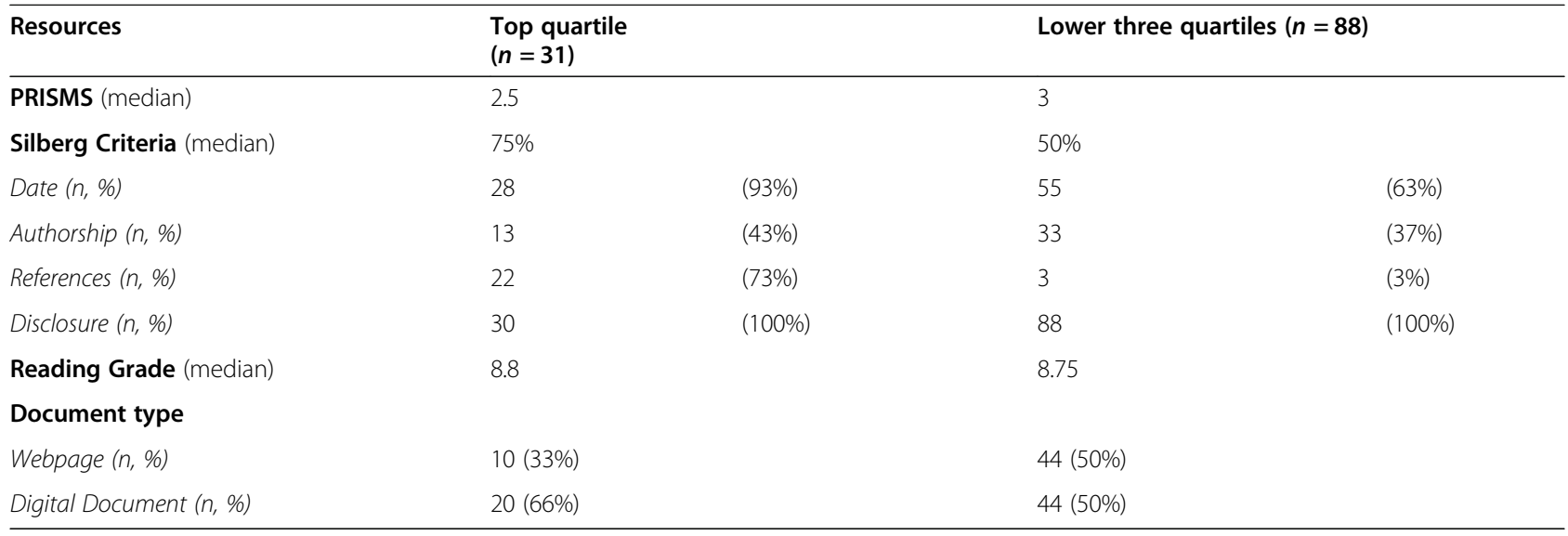

To some extent, the volume of resources surrounding diagnosis and early treatment decision-making for people living with brain cancer is commensurate with evidence that this is the most intense period of information seeking for many patients and their carers [5]. This may be particularly evident in aggressive brain cancer, where there is less time to seek information between diagnosis and active management due to the urgent need to commence treatment [25]. However, cancer survivors, regardless of cancer type, report having significant unmet information needs once their treatment has been completed [5, 37, 38].

There are few online resources that address brain cancer recurrence, despite the high risk of recurrence for all brain cancers [14]. People with cancer, and their carers, report that their greatest information need during recurrence was clear, honest communication about prognosis, yet this information is not readily available online for people living with brain cancer $[39,40]$. Similarly, there are very few references to palliative and end of life care in any of the resources, which is a significant gap given the poor prognosis of people with brain cancer [2, 4150]. A recent study in the US demonstrated that people living with brain cancer often express fear when discussing palliative care and associate it with end of life [51]. Once they had information about the role of palliative care, people living with brain cancer believed that a palliative approach would enhance their mental wellbeing, and wished for information about palliative care earlier in disease course [51]. They also suggested that they would be more open to palliative care if it was not framed as an end of life intervention [51]. It is highly likely that people living with brain cancer, and their carers, would benefit from early access to information about palliative care so that they can make more informed choices about their treatment and symptom management earlier in their illness trajectory.

\section{Lack of practical self-management advice}

People who have recently completed their primary cancer treatment are often anxious as they transition away from an acute care model into a new phase of living with their cancer, and many experience difficulty when trying to self-manage side effects and recovery from illness [38]. While disease information is a factor in supporting self-management of chronic illnesses, people living with brain cancer also require practical advice to assist them coordinate their treatment, symptom management and activities of daily living [28]. Carers also have a strong need for self-management information as cognitive or memory dysfunction can result in people being with brain cancer being unable to undertake complex tasks such as medication management, and experience behavioural change, which is challenging to manage in the home [6]. Unfortunately, very few resources provide practical self-management advice, such as how to effectively manage: cognitive and behavioural changes, treatment side-effects, rehabilitation; and assess capacity to continue to work and/or drive; as opposed to basic factual disease information for this population.

The paucity of self-management guidance for people living with brain cancer on how to live with cognitive and physical disabilities, disease and treatment side-effects and the importance of rehabilitation, and information for carers on how to assist them, is a missed opportunity. Access to reliable information is critical to enabling people living with brain cancer to make independent, informed decisions that will improve their quality of life and ensure that they feel empowered to engage in medical decisionmaking [17]. Resources that enable people living with brain cancer to engage in rehabilitation at home are of particular importance given the documented reluctance of some clinicians and rehabilitation services to offer people living with brain cancer access to rehabilitation [52]. Clinicians' reluctance to offer rehabilitation to people living with brain cancer may stem from a misconception that 
they are not well enough to participate, have a poor prognosis and/or that rehabilitation has little role in maintaining quality of life for this population [52].

The availability of high quality, accessible and detailed information for carers is also vital to provide support as the person with brain cancer becomes more dependent on their care due to side effects from illness and treatment $[6,11,13]$. High quality guides for carers were available online, and described useful and practical management and planning strategies such as planning care, financial preparations and self-care while caring for someone else. However, these could be improved by reducing the reading grade required.

Given the often fragmented nature of brain cancer care across disciplines and care settings during the acute phase, people living with brain cancer, and their carers, are often required to coordinate their own care [53]. The rapid change in circumstances that accompanies brain cancer diagnosis also creates erosion of potentially supportive social networks [54]. This may result in people living with brain cancer, and their carers, feeling less able to initiate new self-management practices after treatment through lack of stable clinical and social support [53].

There is significant opportunity to provide information on the value of low cost, self-determined, home-based interventions such as: exercise programs to benefit physical health and manage fatigue [55], mindfulness to improve cognitive function [56] and pain management that are specific to or can be tailored to people with brain cancer [57]. This would be of particular use for people living with brain cancer that experience seizures, where caregivers report fear of seizures makes leaving the house difficult [58]. Information about these programs in online resources presents significant advantages to people living with brain cancer. These self-management strategies and programs could be readily integrated with routine clinical care to enhance patient outcomes, be home-based in accordance with the preference of many adults with glioma [59] and enable a feeling of greater control [60]. People with cancer that engage in selfmanagement activities outside of the healthcare context can demonstrate gains in: physical function [55], cognition [61], mental health [62] and pain management [57]. The development of appropriate resources that are accessible and practical has the potential to be of great benefit to people living with brain cancer as well as their carers.

\section{Quality of resources}

Similar to other assessments of online information for various cancers, the quality of resources for brain cancer is highly variable [63]. In this study, resources in the top quartile for quality were more likely to contain information that may assist people living with brain cancer, and their carers, to gauge reliability, such as the date of publication and the inclusion of references to information that support the advice or information provided. Conversely, many resources from the lower three quartiles did not. Interestingly, resources in the top quartile were more likely to be published as a digital document (PDF) than as a webpage. No conclusions can be drawn from this data, but this may be worthy of further examination to determine whether this may be a useful indicator of quality to people with brain cancer. Many resources also exceeded the recommended reading grade level, reducing the accessibility of self-management advice and information about disease.

Consumers of online health information are vulnerable to inaccurate and unreliable information [31]. People living with brain cancer, and their carers, need to be able to readily discern between poor and high quality information or self-management advice, which relies on robust health literacy and evaluation skills [64]. Given people with poor health literacy can demonstrate limited understanding and application of tailored self-management advice given directly by clinicians, it follows that this may be compounded when they are required to use: self-initiated strategies to search for specific information; critical thinking to differentiate quality resources; and depth of understanding to assimilate and act on advice [65]. Consumers seeking information referring to complementary and alternative therapies are at particular risk of accessing unreliable information, as these therapies may not be based on evidence. In part, this gap is recognised by non-government organisations providing information for people living with brain cancer, and their carers, that includes guidance for consumers about how to make informed choices about unproven treatments.

The vulnerability of those with poor health literacy to unreliable online self-management advice, or information, is compounded by the short period of time between brain cancer diagnosis and treatment characteristic of serious and progressive illness, and the urgent need for information early in disease course [5, 25]. Cognitive dysfunction in the form of impaired reasoning, processing and memory may further compound this issue for people living with brain cancer by reducing understanding of disease and therefore participation in care [66]. Omission of details of a self-management resource such as date of publication and use of verifiable evidence sources means people living with brain cancer, and their carers, may not be able to easily judge whether a selfmanagement resource is trustworthy.

Substantive information about advance care planning and appointing guardians or medical decision-makers was rarely included in brain cancer specific resources. This deficit in information is particularly important for people with brain cancer, especially those with high- 
grade disease who have a very poor prognosis, and it has been shown that end of life care discussions occur late in disease course when the patient is most dependent $[2,67]$. Some carer resources made reference to these topics, but there appears to be a need for high quality resources aimed specifically at people with brain cancer to be developed, especially for those with reduced cognition.

Practical self-management resources for people living with brain cancer, including information about disease, should be clearly supported by reliable evidence to enable them to rapidly discern and adopt high quality resources, and be regularly updated to reflect current evidence. Co-designing new brain cancer resource with those affected will ensure that future resources address this populations specific information needs across the brain cancer continuum.

\section{Strengths and limitations}

This study encompassed a detailed, systematic search of online health information that emulated the search habits of consumers. Consumer-friendly search terms were used to search the market-leader in online search engines to simulate a search by a lay-person.

Limitations of this study include that only one search engine and language were used. While resources developed before 2009 were excluded, many websites did not include dates, bringing into question the currency of information in these cases. It should also be noted that a study of this kind can only provide a 'snapshot' of the dynamic online environment that quickly evolves. By limiting to text-based information, we overlooked other kinds of online resources including 'social web' opportunities such as peer support, and mHealth apps.

\section{Implications for research and practice}

The development of evidence-based resources in partnership with consumers, clinicians and researchers would result in relevant, accessible content that is evidence-based. Clinicians need to direct people living with brain cancer, and their carers to the best accessible, evidence-based resources. Having ready access to high quality, reliable information would enable people living with brain cancer, and their carers, to actively participate in planning and undertaking their disease management, and enhance emotional and physical wellbeing.

\section{Conclusion}

This systematic environmental scan has demonstrated that there is a plethora of consumer resources. However, none address all of the needs of adults living with brain cancer or their carers across the cancer care continuum, very few are evidence-based and only a small number meet the recommended readability standards. Very few of the resources were designed for people with cognitive impairment or for people from culturally and linguistically diverse backgrounds or First Nations people. There is a significant gap in online resources that provide practical self-management advice, especially in relationship to: survivorship; living with uncertainty; managing behavioural changes; rehabilitation; recurrence; and transition to palliative care.

\section{Supplementary Information}

The online version contains supplementary material available at https://doi. org/10.1186/s12904-021-00715-4

Additional file 1. Quality and readability analysis of online resources for people living with brain cancer and their carers. A list of all resources captured, including country of origin; type and name of developing organisation; and quality and readability scores.

\section{Acknowledgements}

This research was part of the Audit of National Care Standards, clinical pathways and decision support tools for patients with malignant brain cancer, a project commissioned by Cancer Australia under the Australian Brain Cancer Mission (RFQ1819-02).

\section{Authors' contributions}

CA conceptualised the parameters of the Audit. JLP, TL and NH developed the methodology and analytical plan. IS, DD and IAD undertook data collection and preliminary analysis. IS, NH, TL, MA, SC, DC, GH, DD, IAD and JLP contributed to final analysis and interpretation of the data. All authors approved the final manuscript.

\section{Funding}

This research was part of the Audit of National Care Standards, clinical pathways and decision support tools for patients with malignant brain cancer, a project commissioned by Cancer Australia under the Australian Brain Cancer Mission (RFQ1819-02). The Australia Brain Cancer Mission conceptualised the Audit. Study design, data collection, analysis and interpretation were all undertaken independently of the funding organisation.

Availability of data and materials

The dataset supporting the conclusions of this article is included within the article and its additional file.

Ethics approval and consent to participate

Not applicable, no participant recruitment.

Consent for publication

Not applicable.

Competing interests

The authors declare that they have no competing interests.

\section{Author details}

${ }^{1}$ Improving Palliative, Aged and Chronic Care through Clinical Research and Translation (IMPACCT), Faculty of Health, University of Technology Sydney, Sydney, New South Wales, Australia. ${ }^{2}$ Faculty of Health, University of Technology Sydney, Sydney, New South Wales, Australia. ${ }^{3}$ School of Nursing, Midwifery and Paramedicine, Psychology Building, Curtin University, Perth, Western Australia, Australia. ${ }^{4}$ Australian Brain Cancer Mission, Cancer Australia, Sydney, New South Wales, Australia. 
Received: 27 August 2020 Accepted: 13 January 2021 Published online: 23 January 2021

\section{References}

1. Bray F, Ferlay J, Soerjomataram I, Siegel RL, Torre LA, Jemal A. Global cancer statistics 2018: GLOBOCAN estimates of incidence and mortality worldwide for 36 cancers in 185 countries. CA Cancer J Clin. 2018;68(6):394-424.

2. Allemani C, Matsuda T, Di Carlo V, Harewood R, Matz M, Nikšić M, Bonaventure A, Valkov M, Johnson CJ, Estève J. Global surveillance of trends in cancer survival 2000-14 (CONCORD-3): analysis of individual records for 37513025 patients diagnosed with one of 18 cancers from 322 population-based registries in 71 countries. Lancet. 2018; 391(10125):1023-75.

3. Patel AP, Fisher $\mathrm{L}$, Nichols E, Abd-Allah F, Abdela J, Abdelalim A, Abraha HN, Agius D, Alahdab F, Alam T. Global, regional, and national burden of brain and other CNS cancer, 1990-2016: a systematic analysis for the global burden of disease study 2016. Lancet Neurol. 2019;18(4):376-93.

4. Kochovska S, Luckett T, Agar M, Phillips JL. Impacts on employment, finances, and lifestyle for working age people facing an expected premature death: a systematic review. Palliat Support Care. 2018;16(3): 347-64.

5. Matsuyama RK, Kuhn LA, Molisani A, Wilson-Genderson MC. Cancer patients' information needs the first nine months after diagnosis. Patient Educ Couns. 2013;90(1):96-102

6. Halkett GKB, Lobb EA, Oldham L, Nowak AK. The information and support needs of patients diagnosed with high grade Glioma. Patient Educ Couns. 2010;79(1):112-9.

7. National Health Priority Council. National Service Improvement Framework for Cancer. Canberra: Australian Government Department of Health and Ageing; 2006.

8. Ramsay I, Peters M, Corsini N, Eckert M. Consumer health information needs and preferences: a rapid evidence review, vol. 695. Sydney: Australian Commission on Safety and Quality in Health; 2017.

9. Castleton K, Fong T, Wang-Gillam A, Waqar MA, Jeffe DB, Kehlenbrink L, Gao F, Govindan R. A survey of internet utilization among patients with cancer. Support Care Cancer. 2011;19(8):1183-90.

10. Germeni E, Schulz PJ. Information seeking and avoidance throughout the cancer patient journey: two sides of the same coin? A synthesis of qualitative studies. Psychooncology. 2014;23(12):1373-81.

11. Catt S, Chalmers A, Fallowfield L. Psychosocial and supportive-care needs in high-grade glioma. Lancet Oncol. 2008;9(9):884-91.

12. Moore G, Collins A, Brand C, Gold M, Lethborg C, Murphy M, Sundararajan $\checkmark$, Philip J. Palliative and supportive care needs of patients with high-grade glioma and their carers: a systematic review of qualitative literature. Patient Educ Couns. 2013;91(2):141-53.

13. Sizoo EM, Pasman HRW, Dirven L, Marosi C, Grisold W, Stockhammer G, Egeter J, Grant R, Chang S, Heimans JJ, Deliens L, Reijneveld JC, Taphoorn MJB. The end-of-life phase of high-grade glioma patients: a systematic review. Support Care Cancer. 2014;22(3):847-57.

14. Garcia CR, Slone SA, Pittman T, St. Clair WH, Lightner DD, Villano JL. Comprehensive evaluation of treatment and outcomes of low-grade diffuse gliomas. PLoS One. 2018;13(9):e0203639.

15. Eheman CR, Berkowitz Z, Lee J, Mohile S, Purnell J, Marie Rodriguez E, Roscoe J, Johnson D, Kirshner J, Morrow G. Information-seeking styles among cancer patients before and after treatment by demographics and use of information sources. J Health Commun. 2009;14(5):487-502.

16. Kim H, Xie B. Health literacy in the eHealth era: a systematic review of the literature. Patient Educ Couns. 2017;100(6):1073-82.

17. Lee K, Hoti K, Hughes JD, Emmerton LM. Consumer use of "Dr Google": a survey on health information-seeking behaviors and navigational needs. J Med Internet Res. 2015:17(12):e288.

18. McCorkle R, Ercolano E, Lazenby M, Schulman-Green D, Schilling LS, Lorig K, Wagner $\mathrm{EH}$. Self-management: enabling and empowering patients living with cancer as a chronic illness. CA Cancer J Clin. 2011;61(1):50-62.

19. Trappenburg J, Jonkman N J Jaarsma T, van Os-Medendorp H, Kort H, de Wit N, Hoes A, Schuurmans M. Self-management: one size does not fit all. Patient Educ Couns. 2013;92(1):134-7.

20. DeMarco J, Nystrom M, Salvatore K. The importance of patient education throughout the continuum of health care. J Cons Health Internet. 2011; 15(1):22-31.
21. Hibbard JH. Patient activation and the use of information to support informed health decisions. Patient Educ Couns. 2017:100(1):5-7.

22. Kearney M, Jennrich MK, Lyons S, Robinson R, Berger B. Effects of preoperative education on patient outcomes after joint replacement surgery. Orthop Nurs. 2011;30(6):391-6.

23. Semchuk W. Empowering providers to meet patient information needs: reduce patient anxiety to support adherence. Can Pharm J (Ott). 2004; 137(3):46-9.

24. Guo P, East L, Arthur A. A preoperative education intervention to reduce anxiety and improve recovery among Chinese cardiac patients: a randomized controlled trial. Int J Nurs. 2012;49(2):129-37.

25. Ofran Y, Paltiel O, Pelleg D, Rowe JM, Yom-Tov E. Patterns of informationseeking for cancer on the internet: an analysis of real world data. PLoS One. 2012;7(9):1-7. https://doi.org/10.1371/journal.pone.0045921.

26. Chen J, Mullins CD, Novak P, Thomas SB. Personalized strategies to activate and empower patients in health care and reduce health disparities. Health Educ Behav. 2016:43(1):25-34.

27. Liberati A, Altman DG, Tetzlaff J, Mulrow C, Gøtzsche PC, loannidis IPA, Clarke M, Devereaux PJ, Kleijnen J, Moher D. The PRISMA statement for reporting systematic reviews and meta-analyses of studies that evaluate healthcare interventions: explanation and elaboration, vol. 339; 2009. p. b2700.

28. Pearce $\mathrm{G}$, Parke $\mathrm{HL}$, Pinnock $\mathrm{H}$, Epiphaniou $\mathrm{E}$, Bourne $\mathrm{CL}$, Sheikh $\mathrm{A}$, Taylor SJ. The PRISMS taxonomy of self-management support: derivation of a novel taxonomy and initial testing of its utility. J Health Serv Res Policy. 2016;21(2):73-82.

29. Louis DN, Perry A, Reifenberger G, Von Deimling A, Figarella-Branger D, Cavenee WK, Ohgaki H, Wiestler OD, Kleihues P, Ellison DW. The 2016 World Health Organization classification of tumors of the central nervous system: a summary. Acta Neuropathol. 2016;131(6):803-20.

30. Hadfield R, Bates J. Overview of Current Knowledge in Brain Cancer Research with a Focus on Survival. Cure Brain Cancer Foundation; 2018.

31. Silberg WM, Lundberg GD, Musacchio RA. Assessing, controlling, and assuring the quality of medical information on the internet: Caveant lector et viewor-let the reader and viewer beware. JAMA. 1997; 277(15):1244-5.

32. Health on the Net Foundation. Health on the Net. 2020; Available from: https://www.hon.ch/en/.

33. Health on the Net Foundation. Tools. Available from: https://www.hon.ch/ en/tools.html.

34. Charnock D, Shepperd S, Needham G, Gann R. DISCERN: an instrument for judging the quality of written consumer health information on treatment choices. J Epidemiol Commun H. 1999;53(2):105-11.

35. Kincaid JP, Fishburne RP Jr, Rogers RL, Chissom BS. Derivation of new readability formulas (automated readability index, fog count and flesch reading ease formula) for navy enlisted personnel. (Branch Report No 8-75) Millington, TN: Chief of Naval Training 359 Actes de la 2ème Conférence Internationale Éducation, Économie et Société Paris 2010: 1975

36. Good Calculators 2020. Flesch-Kincaid Calculator. Available from: https:// goodcalculators.com/flesch-kincaid-calculator/.

37. Cappiello M, Cunningham RS, Tish Knobf M, Erdos D. Breast cancer survivors: information and support after treatment. Clin Nurs Res. 2007:16(4): 278-93.

38. Foster C, Fenlon D. Recovery and self-management support following primary cancer treatment. Br J Cancer. 2011;105(1):S21-S8.

39. Hours PS, Rusenas I, Simmonds MA, Hueford DL. Information needs of families of cancer patients: a literature review and recommendations. J Cancer Educ. 1991;6(4):255-61.

40. Lobb EA, Halkett GK, Nowak AK. Patient and caregiver perceptions of communication of prognosis in high grade glioma. J Neuro-Oncol. 2011; 104(1):315-22.

41. Cancer Council Australia. Understanding Brain Tumours: A guide for people with brain or spinal cord tumours, their families and friends. Sydney; 1995. [updated 2018]. Available from: https://www.cancer.org.au/content/about_ cancer/ebooks/cancertypes/Understanding_Brain_tumours_booklet_April_2 018.pdf

42. Australia BTA. It's okay to ask: questions to ask your healthcare team about your brain tumour and treatment. Canberra: n.d. Available from: https://www.btaa.org.au/sites/default/files/files/It_s_OK_to_Ask_BTAA_ Booklet_v5.pdf 
43. Brain Tumor Foundation of Canada. Adult Brain Tumor Handbook. Ontario, Canada; 2019. [updated 2019]. Available from: https://www.braintumour.ca/ facing-a-brain-tumour/living-with-a-brain-tumour/patient-handbook/

44. Cancer Research UK. If Your Brain Tumour Can't Be Cured. Oxford; 2019. [updated 2019]. Available from: https://www.cancerresearchuk.org/aboutcancer/brain-tumours/living-with/cant-be-cured

45. The Brain Tumour Charity. What happens at the end of life? Hampshire, England: n.d. Available from: https://www.thebraintumourcharity.org/livingwith-a-brain-tumour/what-do-following-terminal-brain-tumour-diagnosis/ what-happens-end-life/.

46. Brain Tumour Ireland. Palliative/End of life support. Dublin, Ireland: n.d. Available from: https://braintumourireland.com/palliative-end-of-life-support/.

47. The Brain Tumour Charity. Preparing for the end of life. Hampshire, England: n.d. Available from: https://www.thebraintumourcharity.org/living-with-abrain-tumour/what-do-following-terminal-brain-tumour-diagnosis/preparingend-life/.

48. The Brain Tumour Charity. Questions to ask Hampshire, England: 2018 [updated 2018]. Available from: https://assets.thebraintumourcharity.org/ live/media/filer_public/2a/11/2a116d2c-23c6-4544-bb00-b98ef5f2172b/ questions-to-ask-brain-tumours-v2-adult-factsheet.pdf.

49. Health Service Executive. Brain tumour (adult), high-grade. Dublin; 2011. [updated 2011]. Available from: https://www.hse.ie/eng/health/az/b/braintumour,-high-grade/treating-a-high-grade-brain-tumour.html

50. University of California San Francisco. Orientation to Caregiving: A Handbook for Family Caregivers of Patients with Brain Tumors. San Francisco; 2013. [updated 2013]. Available from: https://www.btaa.org.au/ sites/default/files/files/Caregivers\%20Handbook_2nd\%20ed_FINAL.pdf

51. Vierhout M, Daniels M, Mazzotta P, Vlahos J, Mason WP, Bernstein M. The views of patients with brain cancer about palliative care: a qualitative study. Curr Oncol Rep. 2017;24(6):374.

52. McCartney A, Butler C, Acreman S. Exploring access to rehabilitation services from allied health professionals for patients with primary high-grade brain tumours. J Palliat Med. 2011;25(8):788-96.

53. Langbecker $D$, Janda $M$, Yates $P$. Health professionals' perspectives on information provision for patients with brain tumours and their families. Eur J Cancer Care. 2013;22(2):179-87.

54. Cubis $L$, Ownsworth $T$, Pinkham MB, Chambers $S$. The social trajectory of brain tumor: a qualitative metasynthesis. Disabil Rehabil. 2018;40(16):1857-69.

55. Gehring K, Kloek CJJ, Aaronson NK, Janssen KW, Jones LW, Sitskoorn MM, Stuiver MM. Feasibility of a home-based exercise intervention with remote guidance for patients with stable grade II and III gliomas: a pilot randomized controlled trial. Clin Rehabil. 2018;32(3): 352-66.

56. Biegler KA, Alejandro Chaoul M, Cohen L. Cancer, cognitive impairment, and meditation. Acta Oncol. 2009:48(1):18-26.

57. Miaskowski C, Dodd M, West C, Schumacher K, Paul SM, Tripathy D, Koo P. Randomized clinical trial of the effectiveness of a self-care intervention to improve cancer pain management. J Clin Oncol. 2004; 22(9):1713-20.

58. McConigley R, Halkett G, Lobb E, Nowak A. Caring for someone with highgrade glioma: a time of rapid change for caregivers. J Palliat Med. 2010; 24(5):473-9.

59. Culos-Reed SN, Leach HJ, Capozzi LC, Easaw J, Eves N, Millet GY. Exercise preferences and associations between fitness parameters, physical activity, and quality of life in high-grade glioma patients. Support Care Cancer. 2017; 25(4):1237-46.

60. Lee V, Cohen SR, Edgar L, Laizner AM, Gagnon AJ. Meaning-making intervention during breast or colorectal cancer treatment improves self-esteem, optimism, and self-efficacy. Soc Sci Med. 2006;62(12): 3133-45.

61. Gehring K, Sitskoorn MM, Gundy CM, Sikkes SA, Klein M, Postma TJ, van den Bent MJ, Beute GN, Enting RH, Kappelle AC. Cognitive rehabilitation in patients with gliomas: a randomized, controlled trial. J Clin Oncol. 2009; 27(22):3712-22.

62. Poggi G, Liscio M, Pastore V, Adduci A, Galbiati S, Spreafico F, Gandola L, Massimino M. Psychological intervention in young brain tumor survivors: the efficacy of the cognitive behavioural approach. Disabil Rehabil. 2009; 31(13):1066-73.

63. Janssen S, Fahlbusch FB, Käsmann L, Rades D, Vordermark D. Radiotherapy for prostate cancer: DISCERN quality assessment of patient-oriented websites in 2018. BMC Urol. 2019;19(1):42.
64. Diviani N, van den Putte B, Giani S, van Weert JC. Low health literacy and evaluation of online health information: a systematic review of the literature. J Med Internet Res. 2015;17(5):e112.

65. Gaglio B, Glasgow RE, Bull SS. Do patient preferences for health information vary by health literacy or numeracy? A qualitative assessment. J Health Commun. 2012;17(sup3):109-21.

66. Ali FS, Hussain MR, Gutiérrez C, Demireva P, Ballester LY, Zhu J-J, Blanco A, Esquenazi $Y$. Cognitive disability in adult patients with brain tumors. Cancer Treat Rev. 2018:65:33-40.

67. Song K, Amatya B, Voutier C, Khan F. Advance Care Planning in Patients with Primary Malignant Brain Tumors: A Systematic Review. Front Oncol. 2016;6(223):1-14. https://doi.org/10.3389/fonc.2016.00223.

\section{Publisher's Note}

Springer Nature remains neutral with regard to jurisdictional claims in published maps and institutional affiliations.
Ready to submit your research? Choose BMC and benefit from:

- fast, convenient online submission

- thorough peer review by experienced researchers in your field

- rapid publication on acceptance

- support for research data, including large and complex data types

- gold Open Access which fosters wider collaboration and increased citations

- maximum visibility for your research: over $100 \mathrm{M}$ website views per year

At BMC, research is always in progress.

Learn more biomedcentral.com/submissions 